\title{
PREREQUISITES FOR THE DEVELOPMENT OF FIBER OPTIC CLUSTER
}

Strategy of the innovation-based development of JSC PNPPK in conditions of the technology (technologicalmode) changeover is shown. Tendencies, environment and conditions for development of the first Russian high-tech fiber optic cluster on the basis of this enterprise are determined.

The current situation clearly shows that Russia is facing serious challenges, one of them being progressive loss of its status of a high-tech country. The main challenges for high-technology companies are predetermined by their limited engineering and personnel resources. Highly effective marketing, engineering, production and managerial solutions are required in such circumstances due to significant expansion of their time prospects. Saving of the market share is considered by experts as the strategic priority for the enterprise in this stage of development. Russian enterprises may stay in the market only if they manage to advance and implement technologies that at the present time are only at the beginning of their life cycle. One of 


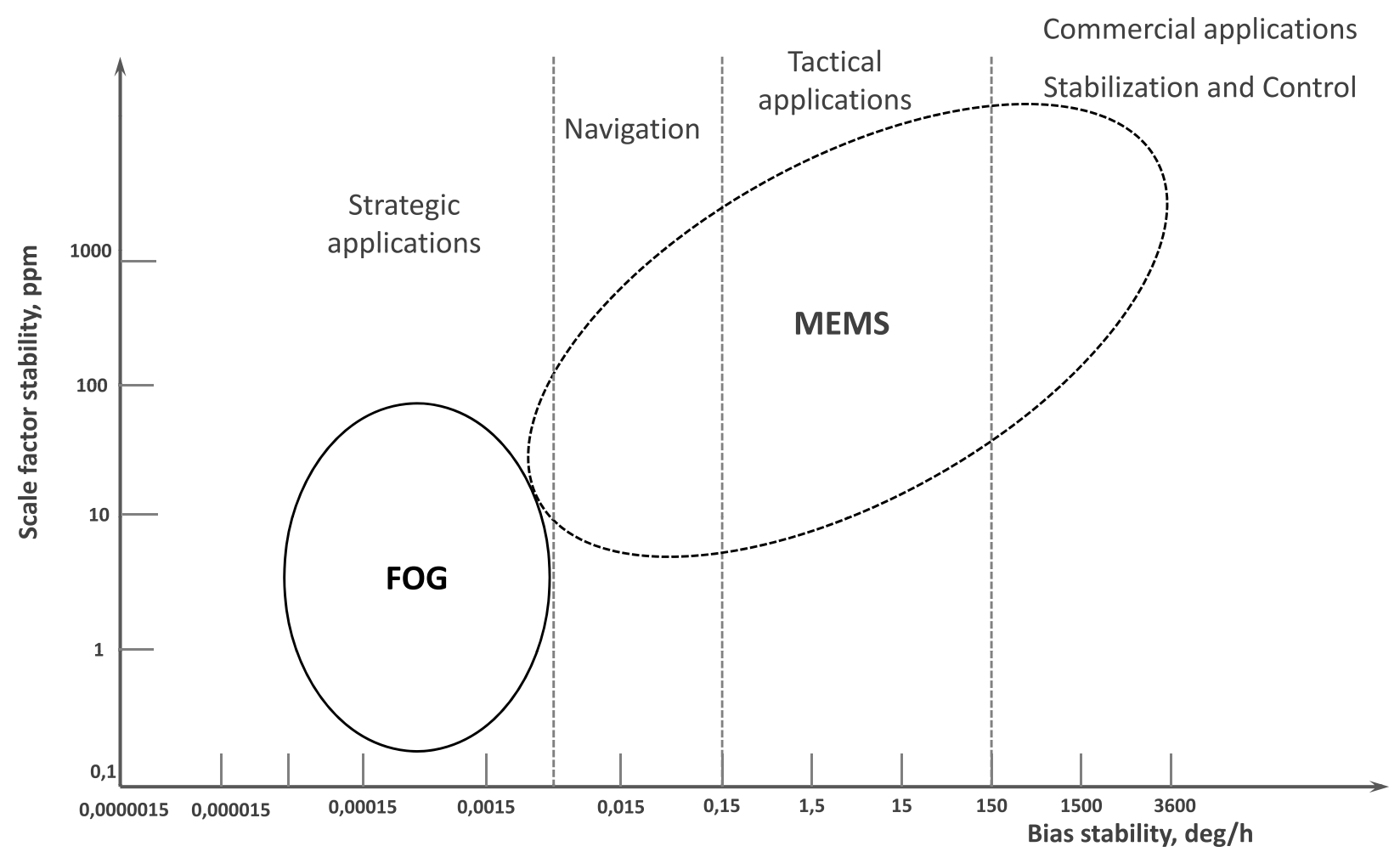

Fig. 1. Forecast of development of inertial navigation systems and source navigation data sensors up to 2030

the tools for handling this task is the development of a cluster economy aimed at concentration of the economic, technical and production capacity. In recent years many territorial subjects of the Russian Federation are developing their local programs of clusterization in various industries.

JSC Perm Scientific-Industrial Instrument Making Company (hereinafter JSC PNPPK, Company) was not passed over by this process. More than 50 years JSC PNPPK has been engaged in developing and producing navigation units and systems for weapons, military and special equipment (WMSE) for aeronautic, marine and land application. The enterprise has a complete production cycle from manufacturing of Inertial Measuring Units (IMU) and their components to assembly and testing of navigation systems.

IMU is the main component of inertial navigation systems used on airborne, space, marine and land vehicles. It measures motion including its type, speed and direction using a set of accelerometers and gyroscopes. Based on the data received from these sensors the computer controls the vehicle position in three-dimensional space.

In the $20^{\text {th }}$ century at the end of the 90 s JSC PNPPK was to choose its way of further development for expanding its share in potential market segments and technologies. Activity in the foreign market, study of competitive environment and customer demand in Russia and abroad have indicated the necessity of changing manufacturing capabilities of the Company in transition from technologies of the 80 -s to those that will be sought for in the $21^{\text {st }}$ century. There existed two main modern technologies in the market at that time: ring laser gyroscopes (RLG) and fiber-optic gyroscopes (FOG). RLG technology was in full bloom and FOG was just starting its way to the market and its positions were weak. There were a lot of issues to be solved in production techniques as well as in marketing.

Having studied the global development trends in the field of inertial sensors, having analyzed market segments including technical and price parameters of inertial sensors as well as technical capability of the enterprise and having estimated innovation costs, in the 90-s the Company has proceeded with development and implementation of FOG technology and strapdown inertial navigation systems on its base. According to Draper Laboratory (Massachusetts Institute of Technology, USA) estimates FOGs and MEMS gyros will dominate in the world market by 2030 (Figure 1).

JSC PNPPK has started arrangement of this high-tech production facility with setting up of a competence centre in the field of a fiber optic engineering - fiber optic cluster.

In 2005-2010 the Company was carrying out a fundamental reform and modernization of production facilities that, on the one hand, will be capable to yield products of the forth technological mode that are still in demand in the navigation equipment market and, on the other hand, to master 


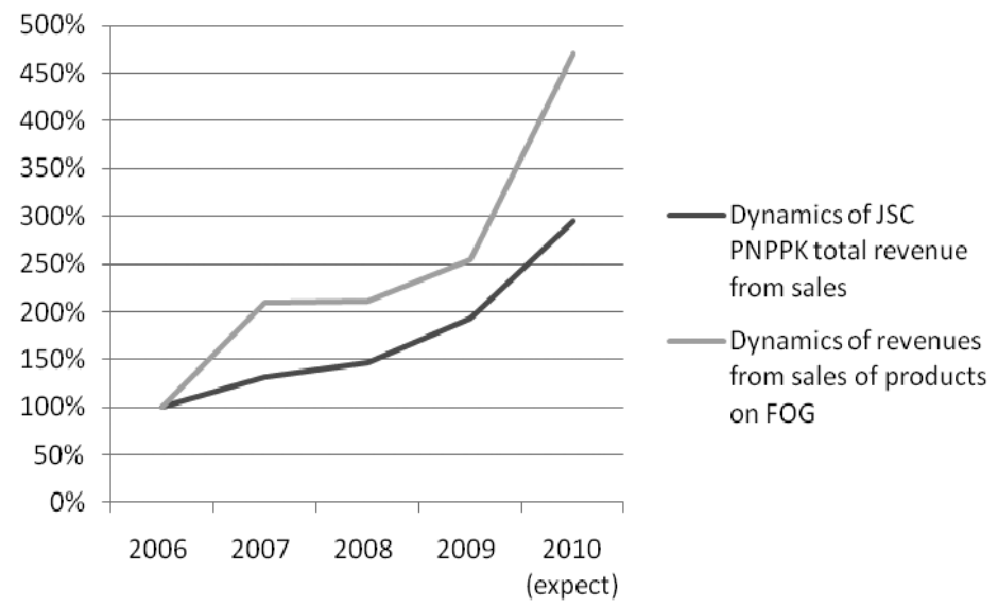

Fig. 2. Dynamics of the total sales revenue and sales revenue of products based on FOG at JSC PNPPK

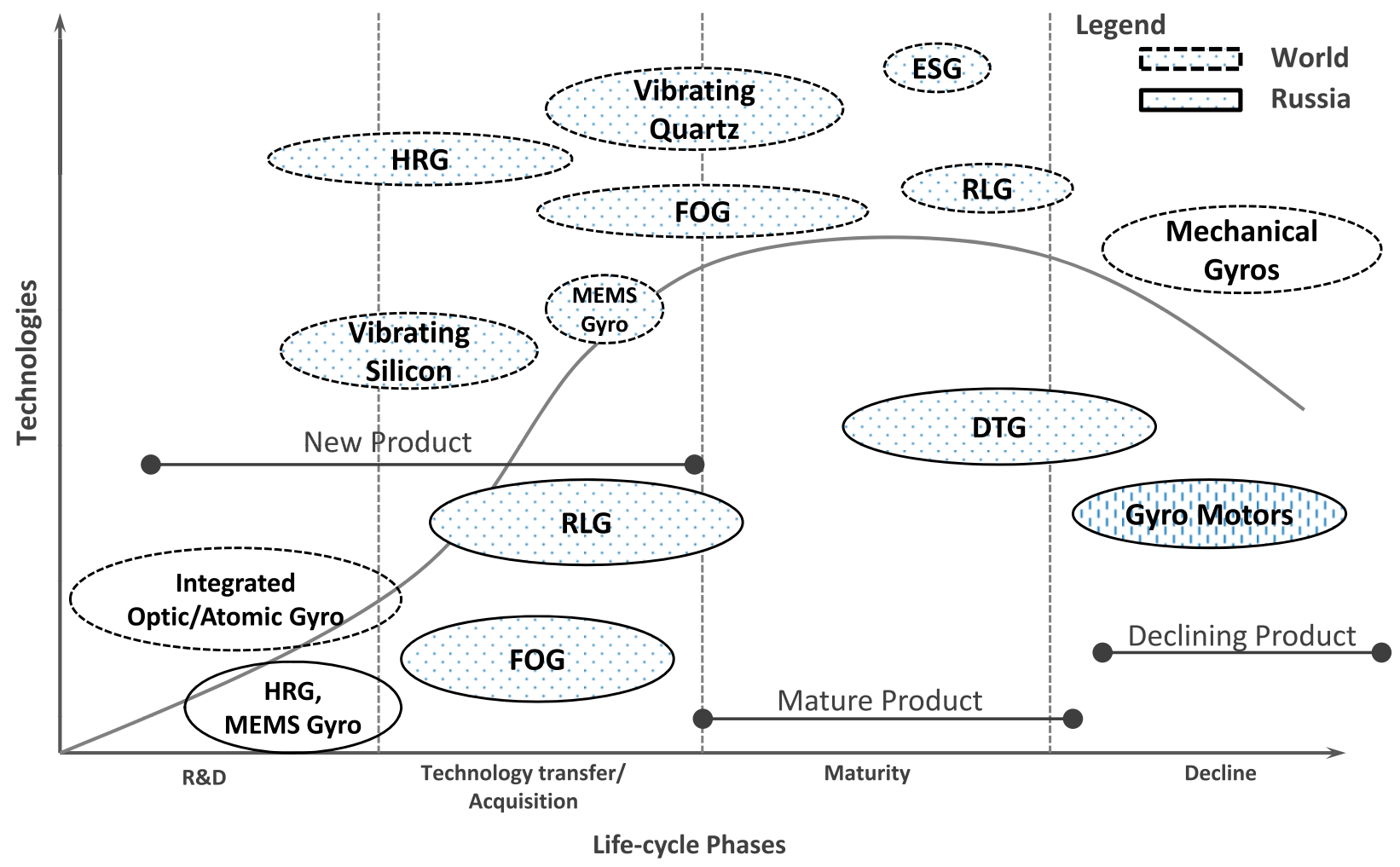

Fig. 3. Position of technologies on the life-cycle curve

technology of the fifth and sixth technological mode - fiber optic instrument engineering.

Time has shown that timely noticed forecasts and decisions taken on their basis proved to be right (see Figure 2).

As seen from Figure 2, since 2006 there has been a steady growth of sales revenue of the products based on FOG that resulted in a more than a twofold increase in the total revenues of JSC PNPPK from 2006 to 2009.

Current research in the world sector of navigation systems totally confirms the forecasts of independent market experts concerning the applied technologies. Ring laser gyros and fiber optic gyros are actively forcing out other types of sensors used for angular motion measurement in WMSE navigation systems.

According to the estimates of «Yole Developpement», market research and strategy consulting company, the market share of IMU on FOGs used for strapdown inertial navigation systems in 2007 was $84 \%$. Sales of IMU on ring laser gyroscopes are gradually going down substituted by IMU on FOG as they are less expensive. In 2007 the market share of IMU on FOG was $35 \%$ of the total IMU world market of and according to forecasts it will increase by $45 \%$ in the next five years ${ }^{1}$.

${ }^{1}$ Yole IMU market 2007-2012 Report September 2007. 


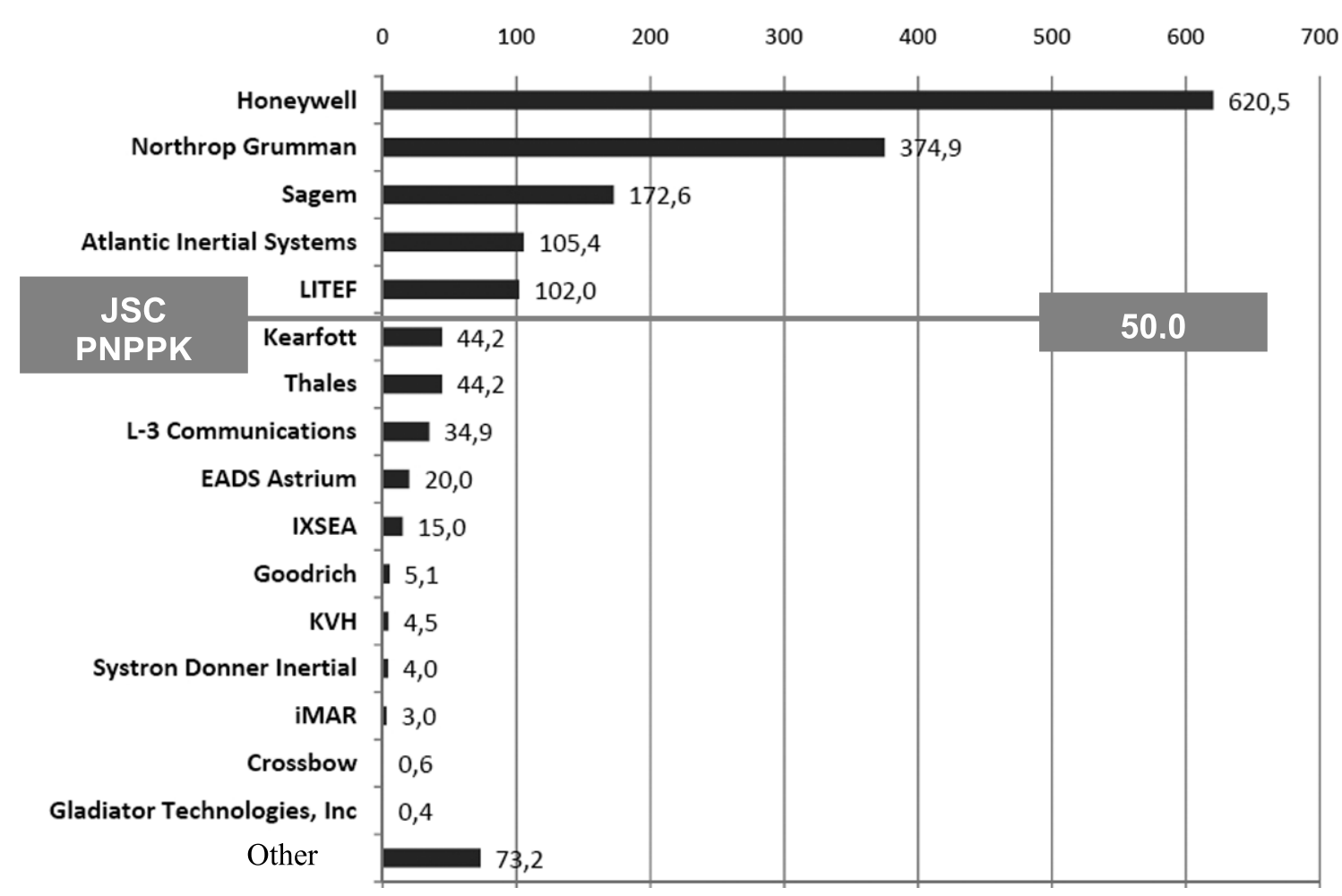

Fig. 4. Rating of major IMU manufacturers in the world market, 2007

All these processes may be plotted and analyzed (Figure 3). This Figure also represents the status of the sensor technology in Russia and worldwide.

As we can see, the world market of IMU based on dynamically tuned gyroscopes (DTG) is clearly declining and their predecessors, gyro motors, withdrew from the market (all of them are mechanical sensors). Ring laser and fiber optic technology occupies the main place in modern aeronautic, space and tactical applications. The accuracy of FOGs is comparable to that of the best RLGs but FOGs surpass them in production effectiveness and service performance. Solid state hemisphere resonant gyros (HRG) and microelectromechanical gyros (MEMS) are passing R\&D stage.

In the rating of major IMU manufacturers in the world market of navigation instruments JSC PNPPK occupies an estimable sixth place (Figure 4) in terms of sales (in US\$M).

Among the leaders in IMU manufacturing there are two American companies: Honeywell (38\% of the market), Northrop Grumman (23\% of the market) and Sagem (France, $11 \%$ of the market). About 20 key players compete in the sector of defense and airborne application of IMU.

JSC PNPPK development strategy calls for implementation of absolutely new innovative solutions, creation of high-grade production facilities and active collaboration with leading scientific institutions of Russia.
The Company draws the attention of scientific community and creates research centers in its territory. In cooperation with Perm State Technical University JSC PNPPK has founded the Institute of Photonics and Optoelectronics. At present the Company is setting up a branch of the Fiber Optic Research Centre of the Russian Academy of Sciences in Perm and is focused on human resources development. In particular, a new discipline was created in Perm State Technical University photonics. Additional courses and practical classes at the enterprise production site were introduced into training programs of Perm educational institutions. Federal and regional authorities take part in this process creating special-purpose support tools: venture capital funds of development are being established, opportunities of investment into production facilities upgrading are being studied and several educative programs are being implemented in cooperation with Rosnano.

Thus, the first Russian high-tech fiber optic cluster is currently being formed on the basis of JSC Perm Scientific-Industrial Instrument Making Company.

\section{References}

1. Romanova O. A., Lavrikova Y. G. Potential of the regional economy clusterization //Aspects of Prognostics. 2008. №4. 